\title{
Study of the interaction of GB Virus C/Hepatitis G Virus Fusion Peptides belonging to the E2 protein with Phospholipid Langmuir Monolayers
}

Silvia Pérez-López ${ }^{\mathrm{a}}$, Marta Espina ${ }^{\mathrm{a}}$, M. José Gómara ${ }^{\mathrm{b}}$, José Luis Fidalgo ${ }^{\mathrm{c}}$, M. Asunción Alsina ${ }^{\mathrm{a}, *}$, Concepció Mestres ${ }^{\mathrm{a}}$ and José Miñones Conde ${ }^{\mathrm{c}}$.

${ }^{a}$ Department of Pharmacy, Pharmaceutical Technology and Physical Chemistry, $\mathrm{IN}^{2} \mathrm{UB}$, Faculty of Pharmacy and Food Sciences, University of Barcelona, Avda Joan XXIII 27-31, 08028 Barcelona, Spain.

${ }^{\mathrm{b}}$ Unit of Synthesis and Biomedical Applications of Peptides, IQAC-CSIC, Jordi Girona 18-26, 08034 Barcelona, Spain.

c Department of Physical Chemistry, Faculty of Pharmacy, University of Santiago de Compostela, Campus Vida, 15706 Santiago de Compostela, Spain.

* Corresponding author:

Name: M. Asunción Alsina

Address: Department of Pharmacy, Pharmaceutical Technology and Physical Chemistry. Faculty of Pharmacy and Food Sciences, University of Barcelona, Avda Joan XXIII 27-31, 08028 Barcelona, Spain. E-mail address: aalsina@ub.edu

Telephone: +34 934024553 


\begin{abstract}
In order to determine the ability of 1,2-dipalmitoyl phosphatidylcholine (DPPC) and 1,2-dioleoyl phosphatidylglycerol (DOPG) to host peptide sequences belonging to the E2 protein of GBV virus $\mathrm{C} / \mathrm{Hepatitis} \mathrm{G}$ virus, the behaviour of Langmuir monolayers formed by these phospholipids and E2 (1226), E2 (354-363) and E2 (chimeric) peptide sequences was analysed from data of surface pressure $(\pi)$ versus area per molecule $(A)$ isotherms, compression modulus $\left(\mathrm{C}_{\mathrm{s}}^{-1}\right)$, excess Gibbs energy of mixing $\left(\Delta \mathrm{G}_{\text {exc }}\right)$ and total Gibbs energy of mixing $\left(\Delta \mathrm{G}_{\text {mix }}\right)$. Three different behaviours were observed. Mixed films of E2 (12-26) with DPPC or DOPC showed negative values for the excess thermodynamic functions, and thus attractive interactions between mixed films components are greater than in ideal films. Mixtures of E2 (354-363) with DPPC or DOPG, exhibited positive values of excess functions, evidencing weaker interactions in the mixed films in relation to those of pure components. Finally, positive and negative excess functions were observed in E2 (chimeric)/DPPC or DOPG mixed films, depending on their composition. In short, the interaction between the phospholipids used in this work as models of cell membranes and E2 peptides varies with the type of phospholipid and the nature of the peptide (size, bulky, hydrophobicity and electric charge).
\end{abstract}

Keywords: $\mathrm{GB}$ virus $\mathrm{C} /$ hepatitis $\mathrm{G}$ virus, chimeric peptide, compression isotherms, phospholipid monolayers, mixed films. 


\section{Introduction}

GB virus $\mathrm{C} /$ hepatitis $\mathrm{G}$ virus (GBV-C/HGV) is the most closely related human virus to hepatitis $\mathrm{C}$ virus (HCV), another member of the Flaviviridae family [1,2]. In contrast to HCV, GBV-C/HGV does not appear to be hepatotrophic, neither replicates in hepatocytes nor causes acute or chronic hepatitis $[3,4]$. In fact, GBV-C/HGV is a lymphotrophic virus that is believed to replicate primarily in the spleen and bone marrow [5].

By itself, GBV-C/HGV infection has not been associated with any specific disease nor does it appear to represent any substantial health risk [6]. However, in the setting of co-infection with human immunodeficiency virus (HIV), current evidence points to $\mathrm{GBV}-\mathrm{C} / \mathrm{HGV}$ offering a benefit in terms of slower progression for HIV related diseases and acquired immunodeficiency syndrome (AIDS). In fact, GBV-C/HGV viremia improves the response to antiretroviral therapy in HIV-infected individuals as measured by a greater reduction of HIV viral load, improved CD4 T cell count and less frequent changes of antiretroviral therapy as compared to those without GBV-C/HGV viremia [7]. In vitro studies confirm these clinical data and show a beneficial effect of GBV-C/HGV on HIV infection $[8,9]$, although the mechanism by which GBV-C modulates HIV infection and AIDS progression is not fully understood. Some studies have focused on the inhibition of the HIV replication by GBV-C/HGV proteins [10,11]. Particularly, it has been reported that E2 protein from GBV-C blocks HIV replication at the binding and/or entry step [12] and, specifically, there have been described several peptide sequences of this protein that interfere with the HIV-1 entry through different mechanisms [13,14].

Furthermore, the E2 protein of other Flaviviridae member, i.e., the hepatitis C virus (HCV), is also involved in the process of cell infection [15]. The understanding of the mechanisms, which regulates the entrance of the virus in human cells through the E2 protein, could undoubtedly shed light on the mechanism by which GBV-C/HGV infects cells and inhibits the replication of HIV.

To get further insight into the GBV-C E2 mediated fusion and examine properties of this protein, we have published some articles using related peptides, one of them corresponding to the amine-terminus part, E2 (12-26) [16], and another one corresponding to the carboxy-terminal, E2 (354-363) [17]. In addition, a chimeric sequence comprising the peptides E2 (12-26) and E2 (354-363) was previously synthesized with the aim of obtaining a new putative antigenic peptide [18]. On the other hand, it is known that the fusion process of the virus and biological membranes plays a vital and important role in many cellular processes $[19,20]$. These peptide-membrane interactions have been studied using different biophysical techniques, where lipid vesicles were mainly used to mimic biological membranes [21]. Between others in vitro models (supported lipid bilayers, liposomes), Langmuir monolayers [22] are traditional but powerful systems for studying intermolecular interactions in a two-dimensional (2D) multi-components systems. Using this technique, we can control the monolayer composition, the surface pressure and the molecular orientation at the air-water interface [23-25]. 
With the aim of building an in vitro membrane model, we have selected two lipids with differing head group, net charge and degree of unsaturation in their hydrocarbon chains: 1,2-dipalmitoyl-snglycero-3-phosphocholine (DPPC), a major component of biological membranes [26], and 1,2-dioleoylsn-glycero-3-[phospho-rac-(1-glycerol)] (sodium salt) (DOPG), an anionic fluid lipid at room temperature. In order to determine the ability of these lipid monolayers to host the selected peptide sequence, we have studied the behaviour of pure and mixed peptide-lipid monolayers spread at the airwater interface by recording the surface pressure $(\pi)$ - area per molecule (A) compression isotherms.

\section{Materials and methods}

\subsection{Lipids and chemicals}

Ultrapure water was obtained by deionization and Nanopure purification coupled to a Milli-Q purification system up to a resistivity of $18.2 \mathrm{M} \Omega \cdot \mathrm{cm}$. Chloroform and methanol were supplied by Merck. DPPC and DOPC were purchased from Avanti Lipids. HEPES buffer and $\mathrm{NaCl}$ were obtained from Sigma-Aldrich. Throughout this study, the aqueous subphase was HEPES buffer $5 \mathrm{mM}$ and $\mathrm{NaCl} 100$ $\mathrm{mM}$ at $\mathrm{pH}$ 7.4.

\subsection{Peptide syntheses and characterization}

The syntheses of peptides E2 (12-26), E2 (354-363) as well as a chimeric sequence were previously described [16-18]. Physicochemical properties of these peptides, such as net charge at $\mathrm{pH}$ 7.4, isoelectric point and Grand Average of Hydropathicity (GRAVY) were predicted using the ExpasyProtParamprogram [27]. The calculation is based on the Kyte-Doolittle scale [28]. The results are shown in Table 1. All the studied peptides are positively charged at pH 7.4, although the E2 (354-367) peptide has a net charge slightly more positive (higher isoelectric point) than the others. The GRAVY of the E2 (12-26) peptide is negative, indicating its hydrophilicity. However, E2 (354-363) is highly hydrophobic as compared with the other two peptides.

\section{Please insert Table 1}

\subsection{Langmuir monolayers}

Peptide/phospholipid mixed monolayers were spread from a chloroform/methanol (9:1:v/v) solution in the concentration range of $0.3-0.5 \mathrm{mg} / \mathrm{mL}$. The stock solutions were mixed in appropriate proportions and dropped with a Hamilton microsyringe on the buffer surface. For the evaporation of the spreading solvent 20 minutes were allowed, after which the monolayers were compressed with the speed of $0.02 \mathrm{~m} / \mathrm{min}$. The surface pressure was monitored continuously by an electronic microbalance with an 
accuracy of $\pm 0.1 \mathrm{mN} / \mathrm{m}$, using a Whatman Chr 1 chromatography paper plate as surface pressure sensor. The Langmuir trough (Nima balance 601) was thermostated at $293 \pm 1.5 \mathrm{~K}$.

\section{Results}

\section{1. $\pi$-A isotherms}

\subsubsection{E2 (12-26)/Phospholipids mixed films}

Figure 1A shows the surface pressure-area per molecule, $\pi$-A, isotherm for pure DPPC monolayer. On compression, a liquid expanded (LE)-liquid condensed (LC) phase transition is observed as a plateau on the isotherm at a surface pressure $\left(\pi_{\mathrm{t}}\right)$ near $5 \mathrm{mN} / \mathrm{m}$. This first order phase transition is typical of the DPPC monolayer at room temperature [29-32]. The collapse occurs at approximately $71 \mathrm{mN} / \mathrm{m}$, according to literature data $[33,34]$.

The behaviour of E2 (12-26) pure monolayer was already studied in a previous article [16] using phosphate buffer saline (PBS) of $\mathrm{pH} 7.4$ as a subphase. However, in the present work we have preferred to use HEPES instead of PBS, to avoid the potential presence of phosphate crystals in the PBS buffer, which could interfere the results. A pseudoplateau in the $\pi$-A isotherm can be seen at $\pi \sim 21 \mathrm{mN} / \mathrm{m}$, a value somewhat higher to the previously published. This pseudoplateau is similar to that observed in the course of pressure/area isotherms of other peptide sequences of the Hepatitis G virus and was attributed to the 2D-3D reorganization of the peptide residues at the $\mathrm{A} / \mathrm{W}$ interface, forming loops and tails $[35,36]$ with the hydrophobic region oriented to the air and the polar groups immersed in the water. Above the pseudoplateau, the surface pressure increases smoothly as the film compression continues until the collapse, which seems to occur around $43 \mathrm{mN} / \mathrm{m}$, although it is not well defined.

At surface pressures below $30 \mathrm{mN} / \mathrm{m}$, the $\pi$-A isotherms of E2 (12-26)/DPPC mixed films of $\mathrm{X}_{\text {peptide }}=0.6$ and 0.8 composition are shifted toward larger areas per molecule in comparison to that of the DPPC component. On the other hand, at higher surface pressures, above $40 \mathrm{mN} / \mathrm{m}$, the isotherms are almost parallel, moving towards greater areas when the DPPC content increases in the mixed films as a consequence of the ejection of the peptide from the monolayer at $\pi \sim 43 \mathrm{mN} / \mathrm{m}$. All the isotherms exhibit some discontinuities, denoting phase changes in the monolayers. The first refers to the LE-LC phase transition of the DPPC, which is visualized as a small plateau in the $\pi$-A isotherms of all the investigated mixtures. The first dashed line in Figure 1A shows the $\pi$ values corresponding to the beginning of this LE-LC phase transition in the mixtures. It can be seen that the transition $\pi$ values and the area per molecule at which the LE-LC phase transition begins, increase with the peptide content of the mixed film, showing that the addition of the peptide to the DPPC monolayer makes it more fluid as a result of increasing the region corresponding to the LE phase. A second discontinuity appears in some isotherms 
$\left(\mathrm{X}_{\text {peptide }}=0.6\right.$ and 0.8$)$ in the region of $\pi$ around $21 \mathrm{mN} / \mathrm{m}$ (second dashed line), which correspond to the loops formation of the peptide residues at the $\mathrm{A} / \mathrm{W}$ interface. A new discontinuity in the $\pi$ - $\mathrm{A}$ isotherms (third dashed line) is seen in the region where it is assumed that the peptide is ejected from the monolayer at a constant $\pi$ value $\left(\pi_{\mathrm{c}}\right.$ peptide $\left.43 \mathrm{mN} / \mathrm{m}\right)$, i.e. practically at the same pressure that the pure peptide is expelled from the monolayer. Finally, the last discontinuity in the $\pi$-A isotherms (fourth dashed line) corresponds to the DPPC collapse, which can be visualized only in monolayers with $\mathrm{X}_{\text {peptide }}<0.8$, the

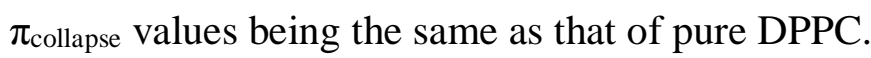

\section{Please insert Figure 1}

A very useful method for characterise the physical state and phase transitions of monolayers is to examine values of the compressibility modulus $\left(\mathrm{C}_{\mathrm{s}}^{-1}\right)$, defined as $-A(d \pi / d A)$. The higher $\mathrm{C}_{\mathrm{s}}^{-1}$ value, the more rigid the monolayer is. Figure $1 \mathrm{~B}$ shows $\mathrm{C}_{s}^{-1}$ versus $\pi$ plots, where it is observed that the addition of peptide molecules to DPPC monolayer causes a remarkable decrease in $\mathrm{C}_{s}^{-1}$ values, i.e. mixed films are more fluid upon increasing their peptide content. On the other hand, with the increasing peptide content in the DPPC monolayers, the LE-LC phase transition of the DPPC (visualized as a minimum in $\mathrm{C}_{\mathrm{s}}^{-1}-\pi$ curves) clearly shifts to slightly higher surface pressures (see inset of Figure 1B). Indeed, the $\pi_{\text {transition }}$ values vary from $4.5 \mathrm{mN} / \mathrm{m}$ (in the case of pure DPPC) to $7 \mathrm{mN} / \mathrm{m}$ (for the mixture with $\mathrm{X}_{\text {peptide }}=0.8$ composition). Others minima in $\mathrm{C}_{\mathrm{s}}^{-1}-\pi$ curves are also observed around $21 \mathrm{mN} / \mathrm{m}$ (peptide loops formation). The $\pi_{\text {loops }}$ values corresponding to these minima points vary from approximately $21 \mathrm{mN} / \mathrm{m}$ in the pure peptide film to $26 \mathrm{mN} / \mathrm{m}$ in the $\mathrm{X}_{\text {peptide }}=0.6$ mixture. Interestingly, $\mathrm{C}_{\mathrm{s}}^{-1}-\pi$ curves show clearly other two minimum around $43 \mathrm{mN} / \mathrm{m}$ and $71 \mathrm{mN} / \mathrm{m}$, respectively: the first corresponding to the peptide collapse and the second to that of the phospholipid. The existence of two collapses, one for each component, evidences components immiscibility at high surface pressures [37].

\section{Please insert Figure 2}

Due to the unsaturation of the aliphatic chains and to the negatively charged polar group, the DOPG monolayer is more expanded (more compressible) as compared to DPPC. Indeed, Figure 2B shows that the DOPG monolayer exhibits a LE state along the compression $\left(\mathrm{C}_{\mathrm{s}}^{-1}\right.$ values do not exceed of $95 \mathrm{mN} / \mathrm{m}$ ). On the other hand, the addition of peptide molecules to the DOPG monolayer provokes a gradual decrease of $\mathrm{C}_{\mathrm{s}}^{-1}$ values. This high compressibility resulted in a drastic diminution of the DOPG collapse pressure, around $46 \mathrm{mN} / \mathrm{m}$ (Figure 2A), in relation to that of DPPC. The isotherms show that at $\pi$ $\leq 22.5 \mathrm{mN} / \mathrm{m}$ all mixed films occupy areas per molecule lower than the pure components, although there are differences between them according to the region of surface pressures under consideration. Thus, at 
surface pressures below approximately $17 \mathrm{mN} / \mathrm{m}$, the mixed film of $\mathrm{X}_{\text {peptide }}=0.4$ is the one with the lowest areas per molecule, while at $\pi>17 \mathrm{mN} / \mathrm{m}$ the most "condensed" film corresponds to the mixture with $\mathrm{X}_{\text {peptide }}=0.8$ composition. This behaviour suggests the existence of attractive interactions between film components, depending on the compression state of the monolayer, i.e. the packing of the molecules at the $\mathrm{A} / \mathrm{W}$ interface. Thus, the existence of components miscibility is evident. The discontinuities at $\pi$ values between $17 \mathrm{mN} / \mathrm{m}$ and $22 \mathrm{mN} / \mathrm{m}$ are attributed to the folding of the peptide. In the $\mathrm{C}_{\mathrm{s}}^{-1}-\pi$ curves, the minimum points corresponding to the loops formation are observed with more clarity: $\pi_{\text {loops }}$ values vary with the composition of the system.

\subsubsection{E2 (354-363)/Phospholipids mixed films}

Figure 3A. shows that for pure E2 (354-363) monolayer the lift-off area per molecule is about 275 $\AA^{2} /$ molecule, a consistent value with similar peptides [25], but much higher than that of the E2 (12-26) peptide (150 $\AA^{2} /$ molecule). This could be due to its greater bulkiness and hydrophobicity. The change of slope in the $\pi$-A isotherm, giving rise to the appearance of the characteristic pseudoplateau, is attributed to $2 \mathrm{D}-3 \mathrm{D}$ molecular rearrangement of the peptide, and occurs at a $\pi$ value about $11 \mathrm{mN} / \mathrm{m}$, considerably lower than that of the E2 (12-26) peptide. On the other hand, the pseudoplateau is larger and flatter, and the monolayer collapse pressure could not be obtained.

\section{Please insert Figure 3}

The recorded isotherms for E2 (354-363)/DPPC mixed monolayers at $\pi \leq 15 \mathrm{mN} / \mathrm{m}$ are more expanded (more fluid) than pure DPPC film, and are displaced toward that of the peptide, showing areas per molecule much larger than that of pure DPPC. Thus, the presence of DPPC in the mixed films seems to be irrelevant. Only in the mixed film with $\mathrm{X}_{\text {peptide }}=0.2$, the LE-LC phase transition corresponding to

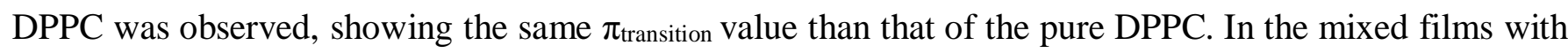
$\mathrm{X}_{\text {peptide }}=0.2-0.6$ composition the values of the collapse pressure could be recorded: the $\pi_{\text {collapse }}$ values match that for pure phospholipid.

In E2 (354-363)/DOPG mixed films (Figure 3B), the addition of peptide to the monolayer of DOPG also causes a deep shift of isotherms towards larger areas per molecule in comparison to that of phospholipid and peptide. These shifts of the isotherms could be due to unfavourable interactions between the film components and to the disturbance provoked by the peptide molecules into more ordered DOPG monolayer. For the mixture with $\mathrm{X}_{\text {peptide }}=0.8$ composition the collapse could not be achieved, but the other mixed monolayers collapse at the same surface pressures as pure DOPG. 


\subsubsection{E2 (Chimeric)/Phospholipids mixed films}

The monolayer of chimeric peptide shows a lift-off area of $550 \AA^{2} /$ molecule (Figure 4A). Given that this peptide contains 28 amino acids, the mean area per residue is approximately $20 \AA^{2}$, a value consistent with results for other peptides, with well-extended horizontal orientation at the A/W interface [38-40]. Under the conditions of our assay, the chimeric monolayer collapse was not reached. The isotherms corresponding to the E2 (chimeric)/DPPC mixed films are situated between those of pure components and the addition of peptide molecules to the DPPC monolayer causes a drastic decrease in $\mathrm{C}_{\mathrm{s}}{ }^{-}$ ${ }^{1}$ values (Figure 4B). In the region of $X_{\text {peptide }} \leq 0.4$, the surface pressure corresponding to the LE-LC phase transition of the DPPC monolayer (minimum points in $\mathrm{C}_{\mathrm{s}}^{-1}-\pi$ curves) increases slightly from 4.5 $\mathrm{mN} / \mathrm{m}$ in the pure DPPC film to $5.3 \mathrm{mN} / \mathrm{m}$ in the mixture with $\mathrm{X}_{\text {peptide }}=0.4$ composition (inset of the figure). In mixtures with $\mathrm{X}_{\text {peptide }} \geq 0.4$ the LE-LC phase transition disappears. When the mixed films were compressed in the region corresponding to the peptide loops formation, the $\mathrm{C}_{\mathrm{s}}^{-1}$ values remain practically constants $\left(\mathrm{C}_{\mathrm{s}}^{-1} \sim 20 \mathrm{mN} / \mathrm{m}\right)$ and the slopes of the $\mathrm{C}_{\mathrm{s}}^{-1}-\pi$ curves are practically zero. For any point in this region, the surface pressure $\left(\pi_{\text {loops }}\right)$ is independent of mixtures composition. The other two minima observed in the $\mathrm{C}_{\mathrm{s}}^{-1}-\pi$ plots at approximately $40 \mathrm{mN} / \mathrm{m}$ and $70 \mathrm{mN} / \mathrm{m}$ correspond, respectively, to the peptide and DPPC collapses. This behaviour proves the existence of components immiscibility.

\section{Please insert Figure 4}

At surface pressures below $25 \mathrm{mN} / \mathrm{m}$, all isotherms corresponding to E2 (chimeric)/DOPG mixed films are situated between those of pure components (Figure 5A), although there is not the same distance between them, i.e. the addition of the peptide to the DOPG monolayer causes uneven increase in its area per molecule, which depends on the composition of the mixed film. The mixed monolayer of $\mathrm{X}_{\text {peptide }}=0.2$ collapses at the same surface pressure than DOPG $(\sim 45 \mathrm{mN} / \mathrm{m})$. In mixed films with greater peptide content, the collapse could not be reached. As for the previously studied systems, the increase of peptide molecules into the DOPG monolayers causes a significant decrease in $\mathrm{C}_{\mathrm{s}}^{-1}$ values, independently its composition (Figure 5B). Interestingly, the surface pressure values corresponding to the looping formation of peptide residues (minimum points in $\mathrm{C}_{s}^{-1}-\pi$ plots) decrease with increasing the peptide content in the mixed films.

\section{Please insert Figure 5}

\subsection{Excess properties}

For quantitative information about the interaction between the molecules in the mixed films, the excess Gibbs energy of mixing was calculated applying Goodrich [41] and Pagano [42] approaches: 
$\Delta G_{\text {exc }}=N \int_{\pi^{*}}^{\pi}\left(A_{1,2}-X_{1} A_{1}-X_{2} A_{2}\right) d \pi$, where $\mathrm{A}_{1}, \mathrm{~A}_{2}$ and $\mathrm{A}_{1,2}$ are the areas per molecule of pure components and mixed film, respectively. $\mathrm{N}$ is the Avogadro's number. The $\pi$ values selected for the upper integration limit were in the range of surface pressures between $10-40 \mathrm{mN} / \mathrm{m}$. The $\pi^{*}$ value of the lower limit of integration is very close to zero for coherent films [43], so that $\Delta \mathrm{G}_{\mathrm{exc}}$ was calculated taking $\pi^{*}=0$. Thermodynamic stability of the mixed monolayers was confirmed using the values of total Gibbs energy of mixing, calculated according to equation: $\Delta G_{m i x}=\Delta G_{e x c}+\Delta G_{m i x}$ ideal, where the ideal Gibbs energy of mixing can be expressed as: $\Delta G_{m i x}$ ideal $=R T\left(X_{1} \ln X_{1}+X_{2} \ln X_{2}\right)$.

Figure $6 \mathrm{~A}$ shows, for comparison, the $\Delta \mathrm{G}_{\mathrm{exc}}$ values for all studied mixed films at $20 \mathrm{mN} / \mathrm{m}$. For E2 (12-26)/phospholipids mixed monolayers, negative values (in red colour) were obtained whatever the mixed films composition and the type of phospholipid (DPPC or DOPG) were. This behaviour suggests that attractive interactions between the components in the mixed films are stronger and more energetically favoured than those in the ideal films. On the other hand, in Supplementary Information (SI) it is observed that these negative $\Delta \mathrm{G}_{\mathrm{exc}}$ values are enhanced with the increasing surface pressure (Figures SI.1A and SI.1B), according to results in literature [44-48]. This is logical, since the attractive intermolecular interactions become more significant as the molecules are at shorter distances, as occurs when the monolayer is in a more condensed state. For both mixtures (E2 (12-26)/DPPC and DOPG), two minimum values of $\Delta \mathrm{G}_{\mathrm{exc}}$ are reached at the same film compositions $\left(\mathrm{X}_{\text {peptide }} \sim 0.4\right.$ and 0.8$)$.

\section{Please insert Figure 6}

For E2 (354-363)/DPPC and DOPG mixed films (in blue colour), positive values of $\Delta \mathrm{G}_{\text {exc }}$ with a maximum around $\mathrm{X}_{\text {peptide }} \sim 0.2-0.25$ suggest that the molecular interactions between the components are less attractive as compared to ideal mixed monolayers. Consequently, phase separation could be possible, as it occurred in other mixed systems with positive $\Delta \mathrm{G}_{\mathrm{exc}}$ values [46-48]. Besides, the positive values of $\Delta \mathrm{G}_{\mathrm{mix}}$, as it is observed in Figure $6 \mathrm{~B}$, prove that mixed films are thermodynamically less stable as compared to their pure monolayers. This instability is greater in mixtures with DOPG, and increases in both systems upon increasing of the surface pressure (Figures SI.1C and SI.1D). The fact that for these mixed systems the surface pressure values corresponding to the collapse coincide with those of the respective phospholipids (Figures $3 \mathrm{~A}$ and $3 \mathrm{~B}$ ) seems to confirm the peptide ejection from the monolayer at lower surface pressures than that of phospholipids.

For E2 (chimeric)/DPPC mixed system, also positive values of $\Delta \mathrm{G}_{\mathrm{exc}}$ were observed in mixtures of $\mathrm{X}_{\text {peptide }}<0.8$ (Figure 6A, rhombus symbol in black), showing two maxima in the mixed films of $\mathrm{X}_{\text {peptide }}$ $=0.2$ and 0.6. The same behaviour can be seen in the $\Delta \mathrm{G}_{\text {mix }}$ versus peptide molar fraction plot (Figure $6 \mathrm{~B})$. As in the previous systems, the mixed films are unstable at $\pi>5 \mathrm{mN} / \mathrm{m}$, increasing instability with 
the surface pressure (Figure SI.2E). Thus, phase separation in the mixed monolayers can occur at high surface pressures, where two distinct collapses, corresponding to the peptide and the DPPC, were observed in the $\pi$-A isotherms (Figure $4 \mathrm{~A}$ ), confirming this assumption. Beyond $\mathrm{X}_{\text {peptide }}=0.8$, negative $\Delta \mathrm{G}_{\mathrm{exc}}$ and $\Delta \mathrm{G}_{\mathrm{mix}}$ values were obtained.

When DPPC is replaced by DOPG in the mixed films, also positive and negative $\Delta \mathrm{G}_{\text {exc }}$ and $\Delta \mathrm{G}_{\text {mix }}$ values were obtained (Figures 6A and 6B, semi-black pentagons), with a maximum at $\mathrm{X}_{\text {peptide }}=0.2$. This behaviour suggests that weak intermolecular interactions occurred at this low concentration of peptide in the mixed films. Thus, phase separation can occur in this mixture. Interestingly, this mixed monolayer collapses at the same surface pressure as pure DOPG component (see Figure 5), evidencing components immiscibility. Beyond $\mathrm{X}_{\text {peptide }}=0.3$, negative $\Delta \mathrm{G}_{\mathrm{exc}}$ and $\Delta \mathrm{G}_{\mathrm{mix}}$ values were observed, suggesting greater attractive interactions between the molecules in the mixed film in comparison to the ideal behaviour and higher thermodynamic stability than in unmixed films. Similar results showing simultaneous positive and negative deviations from the ideal behaviour were obtained by Hac-Wydro et al. [45].

\section{Discussion}

From the obtained results it is evident that the studied systems have three different behaviours: first, mixed films of E2 (12-26) with DPPC or DOPC show negative $\Delta \mathrm{G}_{\mathrm{exc}}$ and $\Delta \mathrm{G}_{\mathrm{mix}}$ values and thus the attractive interactions between mixed films components are greater than in ideal films, and are thermodynamically stable; second, the mixtures of E2 (354-363) with DPPC or DOPG exhibit positive values of $\Delta \mathrm{G}_{\mathrm{exc}}$ and $\Delta \mathrm{G}_{\mathrm{mix}}$, whatever their composition are, evidencing weaker interactions in the mixed film in relation to those of pure components, and third, positive and negative excess functions were observed in E2 (chimeric)/DPPC or DOPG mixed films, depending on their composition.

\section{Negative deviations from ideal behaviour}

Using the diagram in Figure 7, obtained from the surface pressure values corresponding to the different phase transitions of E2 (12-26)/DPPC mixed films (Figures 1A and 1B), the miscibility of the film-forming components in the mixed system can be determined by applying the Crisp's phase rule [49]: $F=3-q(\mathrm{~F}=$ degrees of freedom and $\mathrm{q}=$ number of surface phases in equilibrium under constant temperature and external pressure). Indeed, the $a-b$ line in Figure 7 is associated with the surface pressure values corresponding to the LE-LC phase transition of the DPPC (Figure 1A). Since these values vary linearly with the composition of the monolayers, $\mathrm{F}=1$ (it is only necessary to specify the surface pressure or the molar fraction to characterize the state of the system during the transition) and consequently, $\mathrm{q}=2$, i.e., along the above-cited line two equilibrium phases coexist, namely: below the line, one $\mathrm{M}_{1}$ phase, presumably composed of peptide and DPPC molecules, both with the hydrophobic chains tilted toward the water surface (close horizontal orientation). Above the $a-b$ line, there is also a homogeneous phase $\left(\mathrm{M}_{2}\right)$, but composed by the same molecules with an almost vertical orientation on the water. Similarly, the 
surface pressures of the $c$ - $d$ line, corresponding to the 2D-3D peptide loops formation, vary with the composition of mixtures, and so, a new homogenous surface phase $\mathrm{M}_{3}$ appears in these mixtures above the cited line, formed by coiled peptide molecules and by DPPC molecules with the above described orientation. Similar behaviour was observed in literature for other mixed systems [50-52]. Both collapse surface pressures corresponding to the peptide ( $e-f$ line) and to DPPC ( $g$ - $h$ line) components do not depend on the monolayer composition, and therefore the number of degrees of freedom is $\mathrm{F}=0$ and $\mathrm{q}=3$, i.e., three phases in equilibrium coexist in these situations: in the first case the two new phases appearing are formed by the collapsed peptide and by pure DPPC molecules, both separated from one another. In the second case ( $g$ - $h$ line), the three phases are formed by the previous two phase and by the DPPC collapsed. According to this phase diagram, E2 (12-26) and DPPC components are miscible only at surface pressures lower than approximately $43 \mathrm{mN} / \mathrm{m}$, which corresponds to the ejection of the peptide from the mixed films. In these conditions the values of the excess functions are negative (Figures 6A and 6B), suggesting the existence of strong attractive interactions between the hydrophobic chains of both components (van der Waals attractive forces) together with ion-dipole attractive interactions between the positively charged peptide and the zwitterionic DPPC. These molecular attractions disturb the peptide looping, which disappears when the content of phospholipid in the mixtures is greater than $40 \%$ (mole percent).

\section{Please insert Figure 7}

When the DPPC is replaced by the negatively charged DOPG, electrostatic attractions with the positively charged peptide headgroups could enhance the attractive interactions, especially when $\mathrm{X}_{\text {peptide }}=$ 0.8 (Figures 2A, 6A and 6B), where the formation of a highly stable complex is suggested. This different behaviour between the two mixed systems could be attributed to the packing differences between the monolayers of both pure components: at high surface pressures the hydrocarbon chains of DPPC monolayer adopt a compact conformation (densely packed chains), which, upon compression, favours the expulsion of the hydrophilic peptide inserted between them. However, the expanded monolayer of DOPG, where the hydrocarbon chains are more flexible and disordered, facilitates the permanence of the peptide molecules into the mixed monolayer, favouring the attraction between the hydrocarbon chains of both components.

\section{Positive deviations from ideal behaviour}

From the molecular point of view the existence of $\Delta \mathrm{G}_{\mathrm{exc}}$ positive values observed in Figure 6 for mixed films of E2 (354-363) with DPPC or DOPG could be attributed to the steric hindrance caused by the bulky and hydrophobic peptide molecules, horizontally oriented, into the more ordered arrangement of the phospholipid monolayers [53-55]. Thus, it is suggested that the polymer strands penetrate into the 
hydrocarbon chains of the phospholipids causing the disturbance of its packed and ordered structure and, consequently, an increase in fluidity and area per molecule of the monolayers, as well as a weakening of molecular interactions between the mixed monolayer components.

The phase diagram for the E2 (chimeric)/DPPC system (Figure 7B) shows that at $\pi \geq 20 \mathrm{mN} / \mathrm{m}$ the surface pressure values corresponding to peptide loops formation, as well as those corresponding to the ejection of chimeric and DPPC films components, are independents of the mixtures composition, thus evidencing components immiscibility. However, at $\pi$ values between $5 \mathrm{mN} / \mathrm{m}$ and $20 \mathrm{mN} / \mathrm{m}$ the components are miscible, coexisting two phases $\mathbf{M}_{1}^{\prime}$ and $\mathbf{M}_{2}^{\prime}$ in equilibrium and exhibiting positive deviations from the ideal behaviour when $\mathrm{X}_{\text {peptide }}<0.8$, as it is shown in Figures SI.1E and SI.2E. Because this mixed system exhibits positive deviations from the ideal behaviour, it is suggested that the region of the chimeric molecule responsible of this behaviour is that corresponding to the E2 (354-363) peptide part, which is characterized by the existence of strong positive deviations. The same can be applied to mixtures of E2 (chimeric)/DOPG when their composition is less than $\mathrm{X}_{\text {peptide }}=0.3$. On the contrary, for this system with peptide molar fraction above 0.3 and for E2 (chimeric)/DPPC of $\mathrm{X}_{\text {peptide }}>0.8$, the negative values of the excess properties (Figures 6A and 6B) are similar to those of E2 (1226)/phospholipids mixed films, suggesting that in this case the region of chimeric molecule involved in the interaction corresponds to the E2 (12-26) peptide, which exhibits negative deviations from the ideal behaviour.

In short, the interaction between the peptide and the phospholipids used in this work as models of cell membranes varies with the type of phospholipid and the nature of the peptide (size, bulky, hydrophobicity and electric charge). Even, when the peptide consists of two amino acid sequences, such as the chimeric peptide studied by us, the results are different depending on the composition of the mixed system and the peptide sequence interacting with the phospholipid.

\section{Conclusions}

Binary systems consisting of DPPC or DOPG with E2 (12-26), E2 (354-363) and E2 (chimeric) peptides were analysed. Surface pressure-area isotherms show that in all cases the addition of peptides to phospholipids monolayers makes them more fluid. For E2 (12-26)/DPPC mixed monolayers, negative deviations from the ideal behaviour were obtained, independently of the surface pressure or the composition of the mixtures, indicating miscibility and non ideality, and suggesting the existence of stronger attractive interactions between the components of the mixed monolayers than in ideal films. When the DPPC is replaced by the negatively charged DOPG, electrostatic attractions with the positively charged peptide headgroups could enhance the attractive interactions, especially when $\mathrm{X}_{\text {peptide }}=0.8$, where the formation of a highly stable complex is suggested. Mixed films of E2 (354-363) with DPPC or DOPG exhibit positive values of excess functions. This behaviour is attributed to the steric hindrance 
caused by the bulky and hydrophobic E2 (354-363) peptide molecules into the more ordered arrangement of the phospholipid monolayers. The mixed system formed by E2 (chimeric)/DPPC when $\mathrm{X}_{\text {peptide }}<0.8$ and the mixture of E2 (chimeric)/DOPG $\left(\mathrm{X}_{\text {peptide }}<0.3\right)$ exhibit positive deviations from the ideal behaviour. On the contrary, for E2 (chimeric)/DOPG system with peptide molar fraction above 0.3 and for E2 (chimeric)/DPPC of $\mathrm{X}_{\text {peptide }}>0.8$, the negative values of the excess properties are similar to those of the E2 (12-26)/phospholipids mixed films.

\section{Acknowledgements}

This work was supported by grants from the Ministerio de Ciencia e Innovación (Secretaría de Estado de Universidades, Dirección General de Programas y Transferencia de Conocimiento, Subdirección General de Proyectos de Investigación, Spain) CTQ 201237589C02-02 and from the Ministerio de Economía, Industria y Competitividad of Spain (MINECO) CTQ2015-63919-R, and the European Regional Development Fund (FEDER).

\section{References}

[1] T.P. Leary, S. Muerhoff, J.N. Simons, T.J. Pilot-Matias, J.C. Erker, M.L. Chalmers, et al., Sequence and genomic organization of GBV-C: a novel member of the flaviviridae associated with human non-A-E hepatitis, J. Med. Virol. 48 (1996) 60-67. doi:10.1002/(SICI)10969071(199601)48:1<60::AID-JMV10>3.0.CO;2-A.

[2] K.E. Reed, C.M. Rice, Overview of hepatitis C virus genome structure, polyprotein processing, and protein properties, in: C.H. Hagedorn, C.M. Rice (Eds.), Curr. Top. Microbiol. Immunol., Springer Berlin Heidelberg, Berlin, Heidelberg, 2000: pp. 55-84. doi:10.1007/978-3-642-59605-6_4.

[3] H.J. Alter, Y. Nakatsuji, J. Melpolder, J. Wages, R. Wesley, J.W.-K. Shih, et al., The incidence of transfusion-associated hepatitis $\mathrm{G}$ virus infection and its relation to liver disease, N. Engl. J. Med. 336 (1997) 747-754. doi:10.1056/NEJM199703133361102.

[4] T. Laskus, M. Radkowski, L.F. Wang, H. Vargas, J. Rakela, Lack of evidence for hepatitis G virus replication in the livers of patients coinfected with hepatitis C and G viruses, J. Virol. 71 (1997) 7804-6. http://www.ncbi.nlm.nih.gov/pubmed/9311866.

[5] T.J. Tucker, H.E.M. Smuts, C. Eedes, G.D. Knobel, P. Eickhaus, S.C. Robson, et al., Evidence that the GBV-C/hepatitis G virus is primarily a lymphotropic virus, J. Med. Virol. 61 (2000) 52-58. doi:10.1002/(SICI)1096-9071(200005)61:1<52::AID-JMV8>3.0.CO;2-L.

[6] P.M. Polgreen, J. Xiang, Q. Chang, J.T. Stapleton, GB virus type C/hepatitis G virus: a nonpathogenic flavivirus associated with prolonged survival in HIV-infected individuals, Microbes Infect. 5 (2003) 1255-1261. doi:10.1016/j.micinf.2003.08.006.

[7] N. Bhattarai, J.T. Stapleton, GB virus C: the good boy virus?. Trends Microbiol. 20 (2012) 124-130. doi:10.1016/j.tim.2012.01.004.

[8] M.T.M. Giret, E.G. Kallas, GBV-C: state of the art and future prospects, Curr. HIV/AIDS Rep. 9 (2012) 26-33. doi:10.1007/s11904-011-0109-1.

[9] H.L. Tillmann, M.P. Manns, GB virus-C infection in patients infected with the human immunodeficiency virus, Antiviral Res. 52 (2001) 83-90. doi:10.1016/S0166-3542(01)00172-3.

[10] Q. Chang, J.H. McLinden, J.T. Stapleton, M.A. Sathar, J. Xiang, Expression of GB virus C NS5A protein from genotypes 1, 2, 3 and 5 and a 30 aa NS5A fragment inhibit human immunodeficiency 
virus type 1 replication in a CD4+ T-lymphocyte cell line, J. Gen. Virol. 88 (2007) 3341-3346. doi:10.1099/vir.0.83198-0.

[11] J. Xiang, J.H. McLinden, Q. Chang, T.M. Kaufman, J.T. Stapleton, An 85-aa segment of the GB virus type C NS5A phosphoprotein inhibits HIV-1 replication in CD4+ Jurkat T cells, Proc. Natl. Acad. Sci. 103 (2006) 15570-15575. doi:10.1073/pnas.0604728103.

[12] S. Jung, M. Eichenmüller, N. Donhauser, F. Neipel, A.M. Engel, G. Hess, et al., HIV entry inhibition by the envelope 2 glycoprotein of GB virus C, AIDS. 21 (2007) 645-647. doi:10.1097/QAD.0b013e32803277c7.

[13] Y. Koedel, K. Eissmann, H. Wend, B. Fleckenstein, H. Reil, Peptides derived from a distinct region of GB virus C glycoprotein E2 mediate strain-specific HIV-1 entry inhibition, J. Virol. 85 (2011) 7037-7047. doi:10.1128/JVI.02366-10.

[14] E. Herrera, S. Tenckhoff, M.J. Gómara, R. Galatola, M.J. Bleda, C. Gil, et al., Effect of synthetic peptides belonging to E2 envelope protein of GB virus $\mathrm{C}$ on human immunodeficiency virus type 1 infection, J. Med. Chem. 53 (2010) 6054-6063. doi: 10.1021/jm100452c

[15] A.T. Yagnik, A. Lahm, A. Meola, R.M. Roccasecca, B.B. Ercole, A. Nicosia, et al., A model for the hepatitis C virus envelope glycoprotein E2, Proteins Struct. Funct. Genet. 40 (2000) 355-366. doi:10.1002/1097-0134(20000815)40:3<355::AID-PROT20>3.0.CO;2-K.

[16] C. Larios, M.A. Busquets, J. Carilla, M.A. Alsina, I. Haro, Effects of overlapping GB virus C/Hepatitis G virus synthetic peptides on biomembrane models, Langmuir 20 (2004) 11149-11160. doi:10.1021/la048551g.

[17] S. Pérez-López, M. Nieto-Suárez, C. Mestres, M.A. Alsina, I. Haro, N. Vila-Romeu, Behaviour of a peptide sequence from the GB virus C/hepatitis $\mathrm{G}$ virus E2 protein in Langmuir monolayers: its interaction with phospholipid membrane models, Biophys. Chem. 141 (2009) 153-161. doi:10.1016/j.bpc.2009.01.007.

[18] M. Fernandez-Vidal, M. Cubero, G. Ercilla, M. Gomara, I. Haro, Application of a chimeric synthetic peptide in the development of a serologic method for the diagnosis of hepatitis $\mathrm{G}$ virus infection, Protein Pept. Lett. 14 (2007) 865-870. doi:10.2174/092986607782110239.

[19] W. Weissenhorn, A. Hinz, Y. Gaudin, Virus membrane fusion, FEBS Lett. 581 (2007) 2150-2155. doi:10.1016/j.febslet.2007.01.093.

[20] J.M. White, Viral and cellular membrane fusion proteins, Annu. Rev. Physiol. 52 (1990) 675-697. doi:10.1146/annurev.ph.52.030190.003331.

[21] J. Guillén, M.R. Moreno, A.J. Pérez-Berná, A. Bernabeu, J. Villalaín, Interaction of a peptide from the pre-transmembrane domain of the severe acute respiratory syndrome coronavirus spike protein with phospholipid membranes, J. Phys. Chem. B. 111 (2007) 13714-13725. doi:10.1021/jp073675y.

[22] R. Maget-Dana, The monolayer technique: a potent tool for studying the interfacial properties of antimicrobial and membrane-lytic peptides and their interactions with lipid membranes, Biochim. Biophys. Acta - Biomembr. 1462 (1999) 109-140. doi:http://doi.org/10.1016/S00052736(99)00203-5.

[23] D.H.J. Lopes, A. Meister, A. Gohlke, A. Hauser, A. Blume, R. Winter, Mechanism of islet amyloid polypeptide fibrillation at lipid interfaces studied by infrared reflection absorption spectroscopy, Biophys. J. 93 (2007) 3132-3141. doi:10.1529/biophysj.107.110635.

[24] M. Meier, X.L. Blatter, A. Seelig, J. Seelig, Interaction of verapamil with lipid membranes and pglycoprotein: connecting thermodynamics and membrane structure with functional activity, Biophys. J. 91 (2006) 2943-2955. doi:10.1529/biophysj.106.089581.

[25] S. Pérez-López, N. Vila-Romeu, M.A. Alsina Esteller, M. Espina, I. Haro, C. Mestres, Interaction of $\mathrm{GB}$ virus $\mathrm{C} /$ hepatitis $\mathrm{G}$ virus synthetic peptides with lipid Langmuir monolayers and large unilamellar vesicles, J. Phys. Chem. B. 113 (2009) 319-327. doi:10.1021/jp806938y.

[26] G. van Meer, I.L. van Genderen, Intracellular lipid distribution, transport, and sorting. A cell biologist's need for physicochemical information, in: H.J. Hilderson, G.B. Ralston (Eds.), Subcell. Biochem. Physicochem. Methods Study Biomembr., Springer US, Boston, MA, 1994: pp. 1-24. doi:10.1007/978-1-4615-1863-1_1. 
[27] E. Gasteiger, C. Hoogland, A. Gattiker, S. Duvaud, M.R. Wilkins, R.D. Appel, et al., Protein identification and analysis tools on the ExPASy Server, in: J.M. Walker (Ed.), Proteomics Protoc. Handb., Humana Press, Totowa, NJ, 2005: pp. 571-607. doi:10.1385/1592598900.

[28] J. Kyte, R.F. Doolittle, A simple method for displaying the hydropathic character of a protein, J. Mol. Biol. 157 (1982) 105-132. doi:10.1016/0022-2836(82)90515-0.

[29] J. Miñones Jr, J.M. Rodríguez Patino, O. Conde, C. Carrera, R. Seoane, The effect of polar groups on structural characteristics of phospholipid monolayers spread at the air-water interface, Colloids Surfaces A Physicochem. Eng. Asp. 203 (2002) 273-286. doi:10.1016/S0927-7757(01)01107-4.

[30] T. Hiranita, S. Nakamura, M. Kawachi, H.M. Courrier, T.F. Vandamme, M.P. Krafft, et al., Miscibility behavior of dipalmitoylphosphatidylcholine with a single-chain partially fluorinated amphiphile in Langmuir monolayers, J. Colloid Interface Sci. 265 (2003) 83-92. doi:10.1016/S0021-9797(03)00483-1.

[31] F. Gerber, M.P. Krafft, T.F. Vandamme, M. Goldmann, P. Fontaine, Fluidization of a dipalmitoyl phosphatidylcholine monolayer by fluorocarbon gases: potential use in lung surfactant therapy, Biophys. J. 90 (2006) 3184-3192. doi:10.1529/biophysj.105.077008.

[32] K.J. Klopfer, T.K. Vanderlick, Isotherms of dipalmitoylphosphatidylcholine (DPPC) monolayers: features revealed and features obscured, J. Colloid Interface Sci. 182 (1996) 220-229. doi: $10.1006 /$ jcis. 1996.0454.

[33] G. Weidemann, D. Vollhardt, Long-range tilt orientational order in phospholipid monolayers: a comparative study, Biophys. J. 70 (1996) 2758-2766. doi:10.1016/S0006-3495(96)79845-4.

[34] K.Y.C. Lee, Collapse mechanisms of Langmuir monolayers, Annu. Rev. Phys. Chem. 59 (2008) 771-791. doi:10.1146/annurev.physchem.58.032806.104619.

[35] C. Larios, J. Miñones Jr, I. Haro, M.A. Alsina, M.A. Busquets, J. Miñones Trillo, Study of adsorption and penetration of E2(279-298) peptide into Langmuir phospholipid monolayers, J. Phys. Chem. B. 110 (2006) 23292-23299. doi:10.1021/jp0628582.

[36] J. Miñones Jr, M. Muñoz, J. Miñones Trillo, I. Haro, M.A. Busquets, M.A. Alsina, Miscibility and Langmuir studies of the interaction of E2 (279-298) peptide sequence of hepatitis G virus/GB virus-C with dipalmitoylphosphatidyl choline and dimiristoylphosphatidyl choline phospholipids, Langmuir 31 (2015) 10161-10172. doi:10.1021/acs.langmuir.5b00712.

[37] G.L. Gaines, Insoluble monolayers at liquid-gas interfaces. I., in: Prigonine (Ed), Interscience Publ. New York, 1966, chapter 6: pp. 281-286.

[38] F. Mc Ritchie, Chemistry at Interfaces, Academic Press, San Diego, 1990.

[39] R. Maget-Dana, D. Lelièvre, A. Brack, Surface active properties of amphiphilic sequential isopeptides: comparison between $\alpha$-helical and $\beta$-sheet conformations, Biopolymers. 49 (1999) 415-423. doi:10.1002/(SICI)1097-0282(19990415)49:5<415::AID-BIP7>3.0.CO;2-J.

[40] D. Dieudonné, A. Gericke, C.R. Flach, X. Jiang, R.S. Farid, R. Mendelsohn, Propensity for helix formation in the hydrophobic peptides $\mathrm{K} 2(\mathrm{LA})(\mathrm{x})(\mathrm{x}=6,8,10,12)$ in monolayer, bulk, and lipidcontaining phases. Infrared and circular dichroism studies, J. Am. Chem. Soc. 120 (1998) 792-799. doi:10.1021/ja9724046.

[41] F.C. Goodrich, Molecular interaction in mixed monolayers, in: Proc. 2nd Int. Congr. Surf. Act., Butterworth, London, 1957.

[42] R.E. Pagano, N.L. Gershfeld, A millidyne film balance for measuring intermolecular energies in lipid films, J. Colloid Interface Sci. 41 (1972) 311-317. doi:10.1016/0021-9797(72)90116-6.

[43] I.S. Costin, G.T. Barnes, Two-component monolayers. II. Surface pressure - area relations for the octadecanol — docosyl sulphate system, J. Colloid Interface Sci. 51 (1975) 106-121. doi:http://dx.doi.org/10.1016/0021-9797(75)90088-0.

[44] T.-H. Chou, C.-H. Chang, Thermodynamic characteristics of mixed DPPC/DHDP monolayers on water and phosphate buffer subphases, Langmuir 16 (2000) 3385-3390. doi:10.1021/la990581.

[45] K. Hac-Wydro, P. Wydro, P. Dynarowicz-Latka, A study of the interaction between dialkyldimethylammonium bromides and tri-n-octylphosphine oxide (topo) in mixed monolayers at the air/water interface, J. Colloid Interface Sci. 278 (2004) 206-214. doi:10.1016/j.jcis.2004.05.014. 
[46] K. Gong, S.-S. Feng, M.L. Go, P.H. Soew, Effects of pH on the stability and compressibility of DPPC/cholesterol monolayers at the air-water interface, Colloids Surfaces A Physicochem. Eng. Asp. 207 (2002) 113-125. doi:10.1016/S0927-7757(02)00043-2.

[47] N. Krasteva, D. Vollhardt, G. Brezesinski, Mixed stearoyl-rac-glycerol/12-(hydroxy)stearoyl-racglycerol monolayers on the air/water interface: Brewster angle microscopy and grazing incidence X-ray diffraction investigation, J. Phys. Chem. B. 104 (2000) 8704-8711. doi:10.1021/jp001479k.

[48] A.K. Panda, K. Nag, R.R. Harbottle, F. Possmayer, N.O. Petersen, Thermodynamic studies on mixed molecular langmuir films. Part 2. Mutual mixing of DPPC and bovine lung surfactant extract with long-chain fatty acids, Colloids Surfaces A Physicochem. Eng. Asp. 247 (2004) 9-17. doi:10.1016/j.colsurfa.2004.07.008.

[49] D.J. Crisp, Surface Chemistry, in: Suppl. Res., Butterwothh, London, 1949: pp. 17-23.

[50] M. Miñones Conde, O. Conde, J.M. Trillo, J. Miñones Jr, Approach to knowledge of the interaction between the constituents of contact lenses and ocular tears: mixed monolayers of poly(methyl methacrylate) and dipalmitoyl phosphatidyl choline, Langmuir 27 (2011) 3424-3435. doi:10.1021/la1051172.

[51] J. Hoyo, E. Guaus, J. Torrent-Burgués, F. Sanz, Biomimetic monolayer films of digalactosyldiacylglycerol incorporating plastoquinone, Biochim. Biophys. Acta 1848 (2015) 13411351. doi.org/10.1016/j.bbamem.2015.03.003.

[52] J. Hoyo, E. Guaus, J. Torrent-Burgués, F. Sanz, Biomimetic monolayer films of monogalactosyldiacylglycerol incorporating plastoquinone, J. Phys. Chem. B 119 (2015) 61706178. doi: 10.1021/acs.jpcb.5b02196.

[53] J.B. Peng, G.T. Barnes, Effect of stearic acid on the surface pressure gradients in poly(methyl methacrylate) monolayers, Langmuir 7 (1991) 3090-3093. doi:10.1021/la00060a031.

[54] G. Capuzzi, P. Lo Nostro, K. Kulkarni, J.E. Fernandez, Mixtures of stearoyl-6-O-ascorbic acid and $\alpha$-tocopherol: a monolayer study at the gas/water interface, Langmuir 12 (1996) 3957-3963. doi:10.1021/la960001y.

[55] L. Zhao, S.-S. Feng, Effects of lipid chain unsaturation and headgroup type on molecular interactions between paclitaxel and phospholipid within model biomembrane, J. Colloid Interface Sci. 285 (2005) 326-335. doi:10.1016/j.jcis.2004.11.032. 


\section{Figure captions}

Figure 1. $\pi$-A isotherms (A) and $\mathrm{C}_{s}^{-1}-\pi$ plots (B) for E2 (12-26)/DPPC mixed films. Inset: $\mathrm{C}_{s}^{-1}-\pi$ plots for the LE-LC phase transition of DPPC.

Figure 2. $\pi$-A isotherms (A) and $\mathrm{C}_{\mathrm{s}}^{-1}-\pi$ plots (B) for E2 (12-26)/DOPG mixed films.

Figure 3. $\pi$-A isotherms for E2 (354-363)/DPPC (A) and E2 (354-363)/DOPG (B) mixed films.

Figure 4. $\pi$-A isotherms (A) and $\mathrm{C}_{\mathrm{s}}^{-1}-\pi$ plots (B) for E2 (chimeric)/DPPC mixed films. Inset: $\mathrm{C}_{\mathrm{s}}^{-1}-\pi$ plots for the LE-LC phase transition of DPPC.

Figure 5. $\pi$-A isotherms (A) and $\mathrm{C}_{\mathrm{s}}^{-1}-\pi$ plots (B) for E2 (chimeric)/DOPG mixed films.

Figure 6. $\Delta \mathrm{G}_{\mathrm{exc}}(\mathrm{A})$ and $\Delta \mathrm{G}_{\mathrm{mix}}(\mathrm{B})$ versus $\mathrm{X}_{\mathrm{E} 2}$ plots at $20 \mathrm{mN} / \mathrm{m}$.

Figure 7. Phase diagrams for E2 (12-26)/DPPC (A) and E2 (chimeric)/DPPC (B) mixed films.

\section{Supporting Information:}

Figure SI.1. $\Delta \mathrm{G}_{\mathrm{exc}}$ versus $\mathrm{X}_{\mathrm{E} 2}$ plots for mixed films at different surface pressures. (A) E2 (12-26)/DPPC, (B) E2 (12-26)/DOPG, (C) E2 (354-363)/DPPC, (D) E2 (354-363)/DOPG, (E) E2 (chimeric)/DPPC, (F) E2 (chimeric)/DOPG.

Figure SI.2. $\Delta \mathrm{G}_{\mathrm{mix}}$ versus $\mathrm{X}_{\mathrm{E} 2}$ plots for mixed films at different surface pressures. (A) E2 (12-26)/DPPC, (B) E2 (12-26)/DOPG, (C) E2 (354-363)/DPPC, (D) E2 (354-363)/DOPG, (E) E2 (chimeric)/DPPC, (F) E2 (chimeric)/DOPG.

\section{Graphical Abstract:}

Isotherms for pure phospholipids (DPPC and DOPG) and peptide sequences (E2 (12-26), E2 (354-363) and E2 (chimeric)) and hydrophobicity profiles of the three peptides.

\section{TABLE 1}

Peptides amino acid sequence, net charge, isoelectric point and grand average hydropathicity

\begin{tabular}{ccrrrr}
\hline Peptide & Amino acid sequence & Net charge & Isoelectric & GRAVY & ES-MS $^{\mathbf{b}}$ \\
E2 (12-26) & E P G L T W Q S C S C R A N G & +1 & 8.3 & -0.667 & $\mathbf{M}^{+}=1608.0$ \\
\hline E2 (354-363) & L A E A R L V P L I & +1 & 11.04 & 1.410 & $\mathbf{M}^{+}=1093.7$ \\
\hline Chimeric & L A E A R L V P L I -GGG- E P G L T W Q S C S C R A N G & +1 & 8.3 & 0.104 & $\mathrm{M}^{+}=2853.0$ \\
\hline
\end{tabular}

\footnotetext{
${ }^{a}$ In red the cationic amino acid, in blue the anionic amino acid.

${ }^{\mathrm{b}}$ Electrospray mass spectrometry (ES-MS)
} 
FIGURE 1
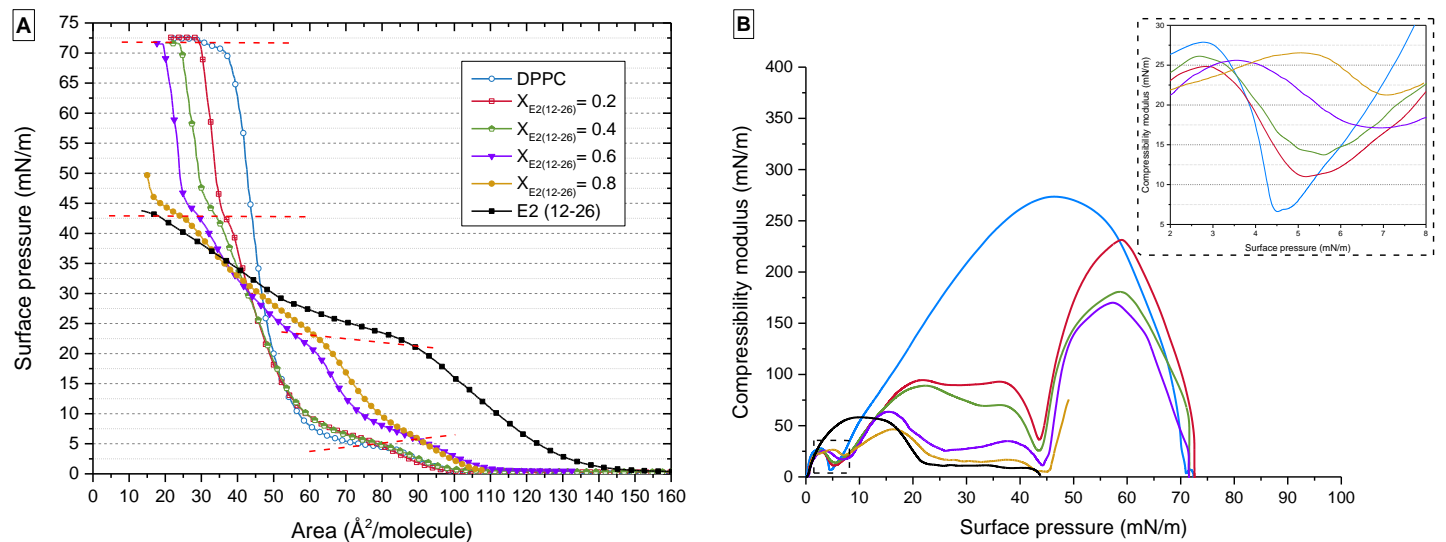

\section{FIGURE 2}
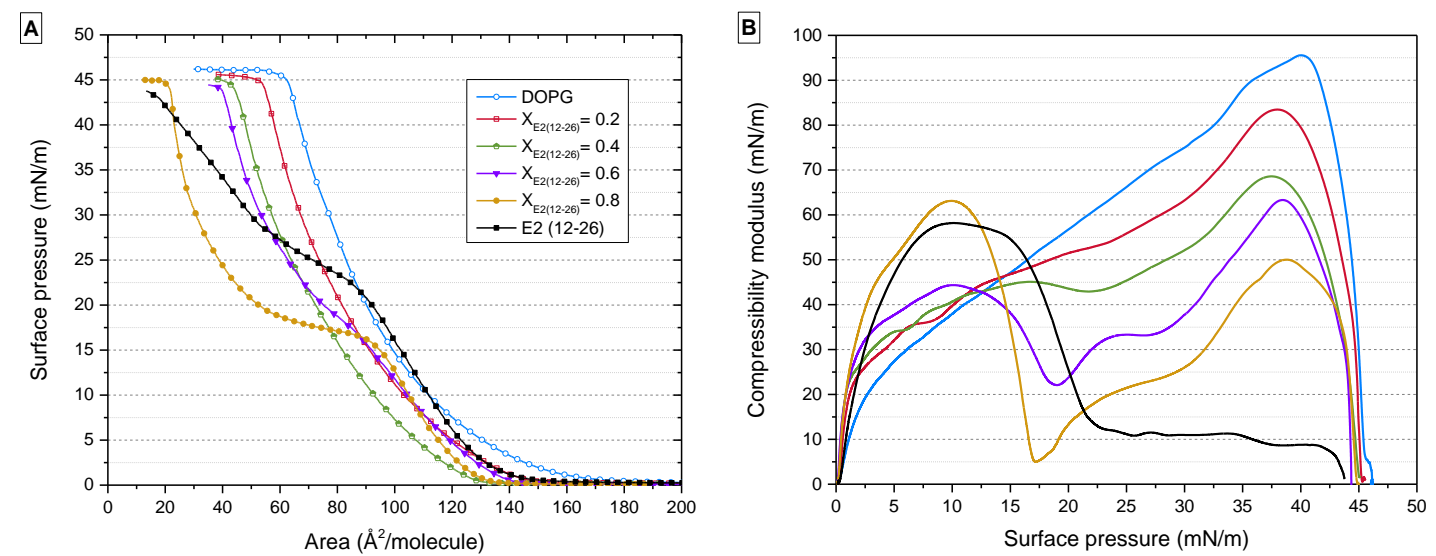

\section{FIGURE 3}
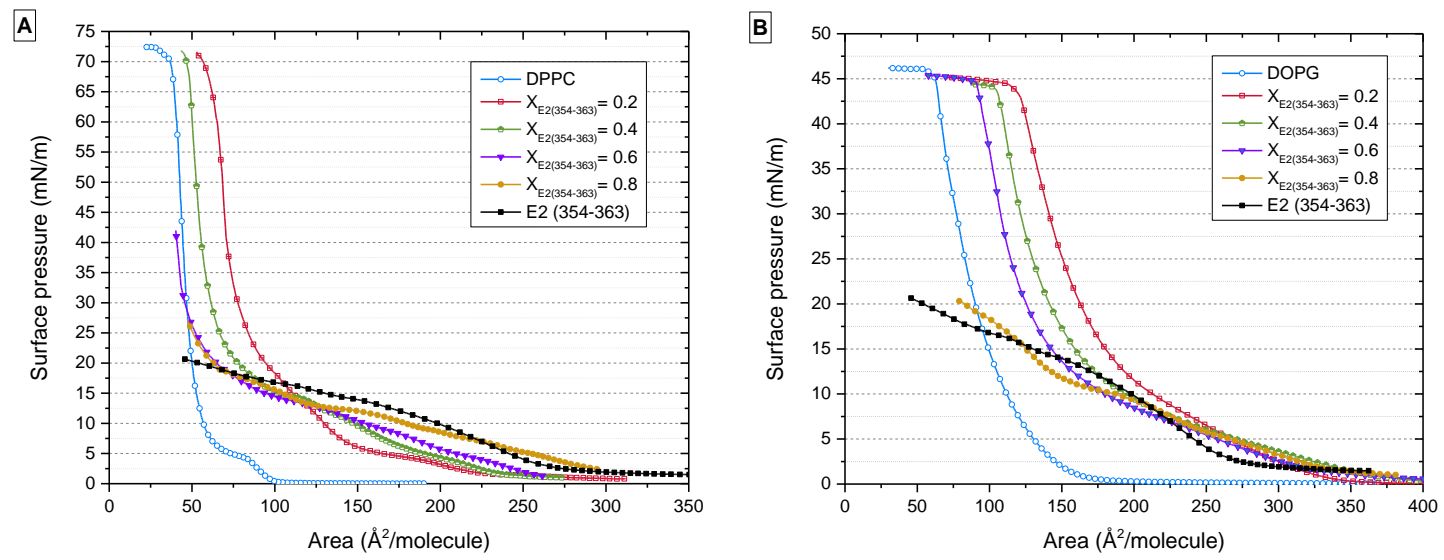
FIGURE 4
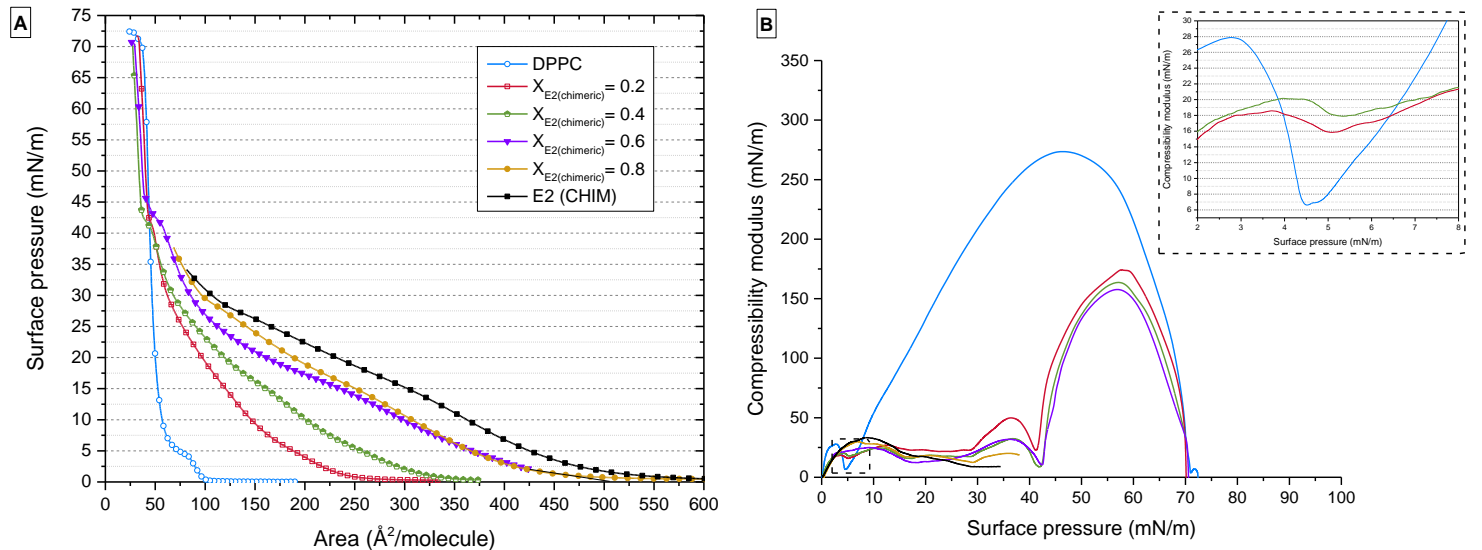

\section{FIGURE 5}
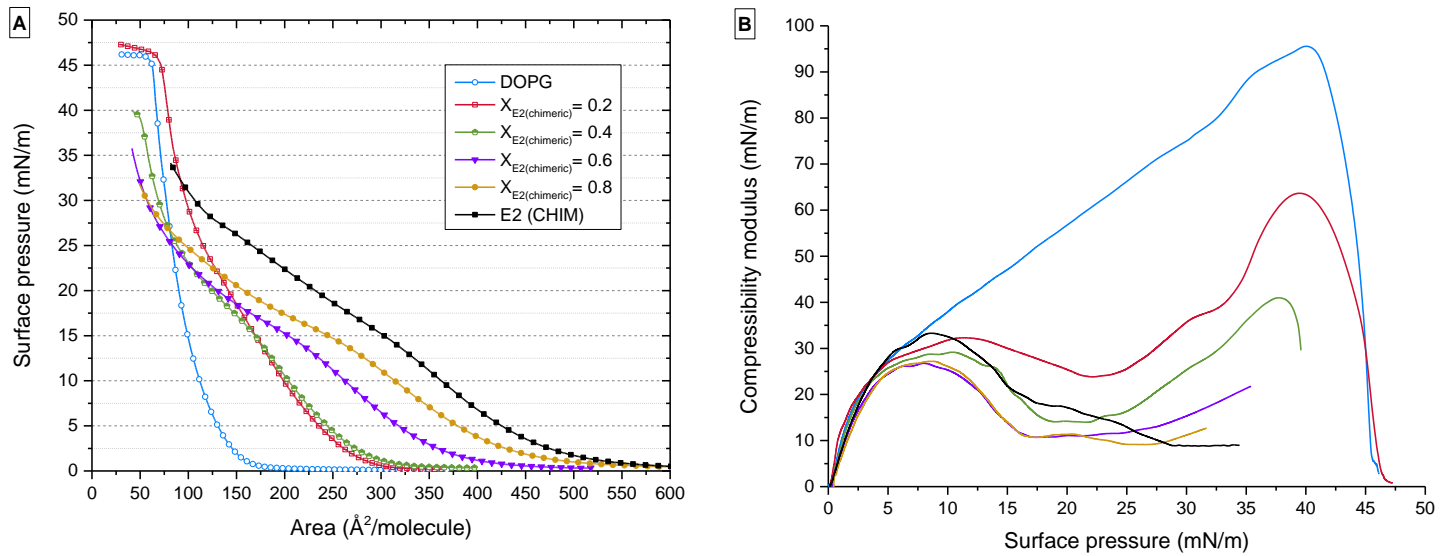
FIGURE 6
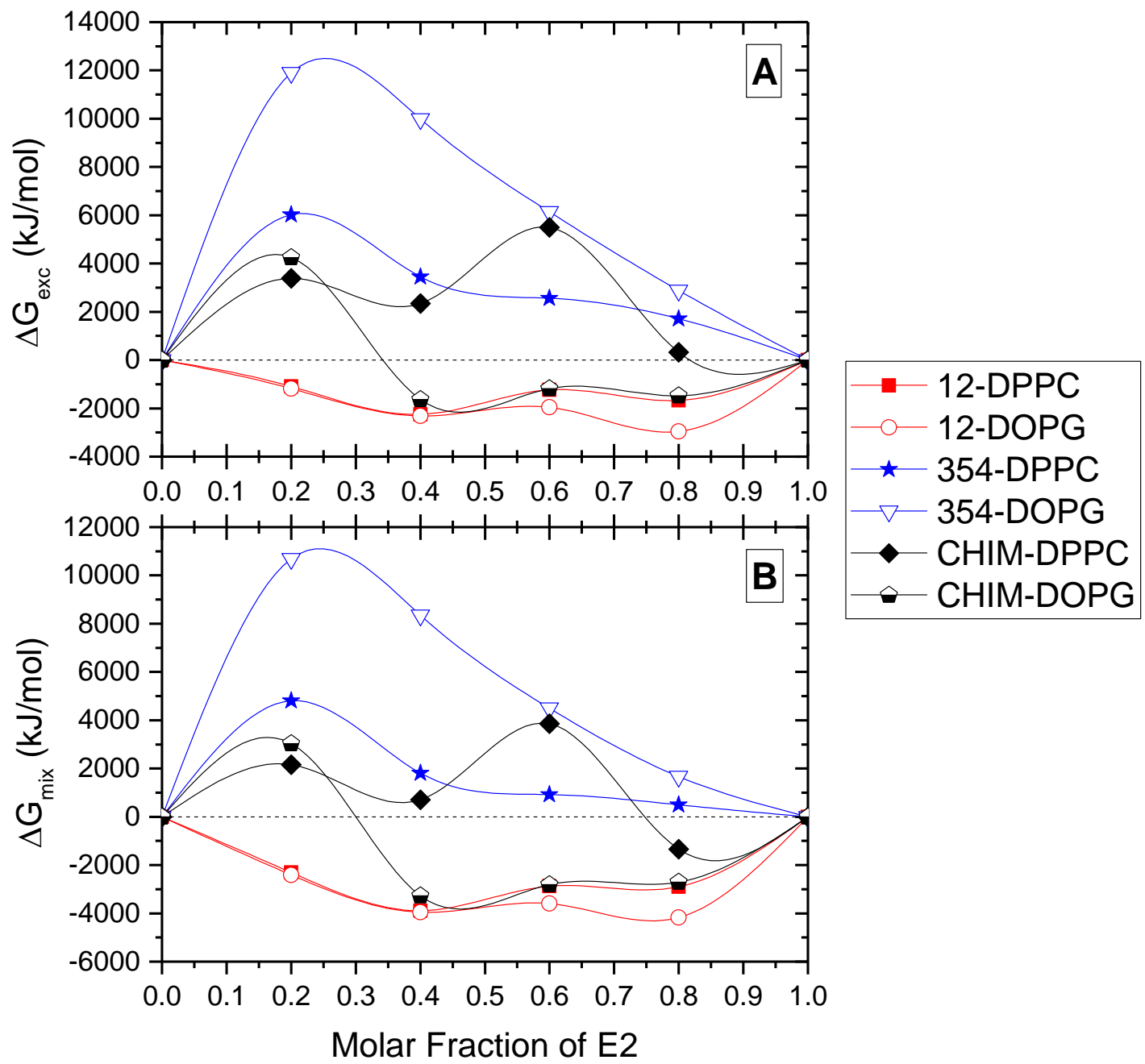
FIGURE 7
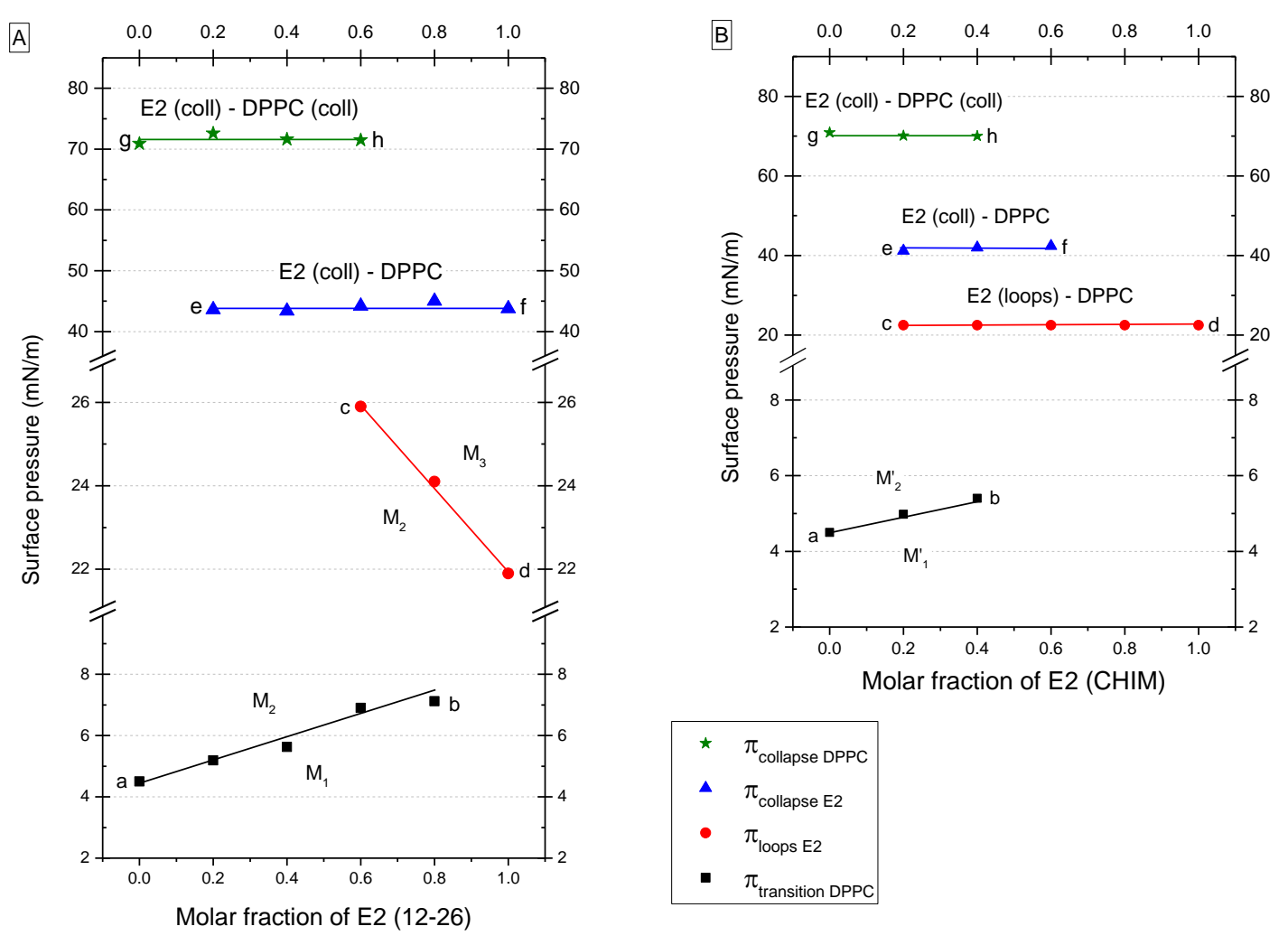

$\begin{array}{ll}\star & \pi_{\text {collapse DPPC }} \\ \text { - } & \pi_{\text {collapse E2 }} \\ \text { - } & \pi_{\text {loops E2 }} \\ \text { - } & \pi_{\text {transition DPPC }}\end{array}$ 


\section{FIGURE SI.1}
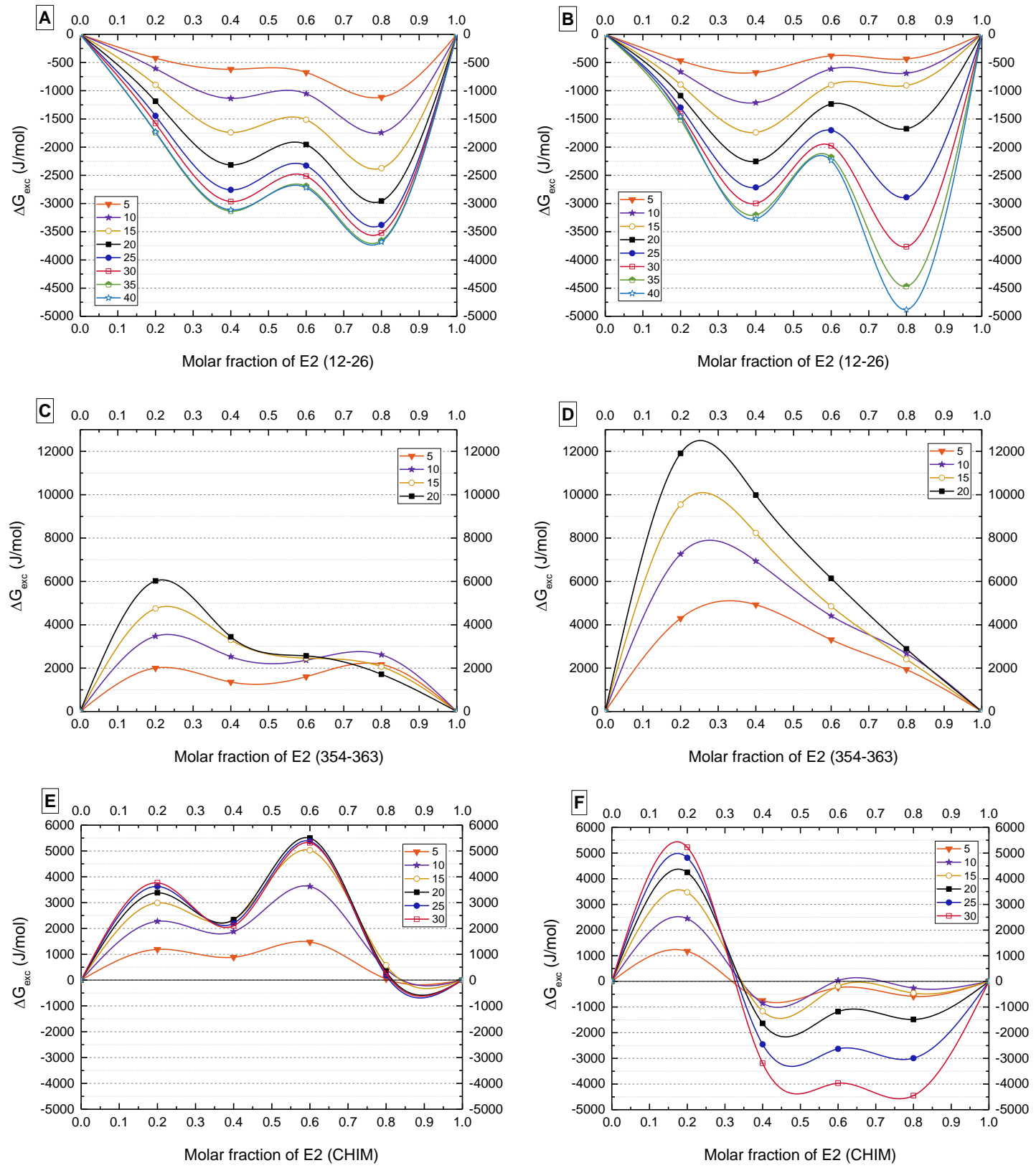


\section{FIGURE SI.2}
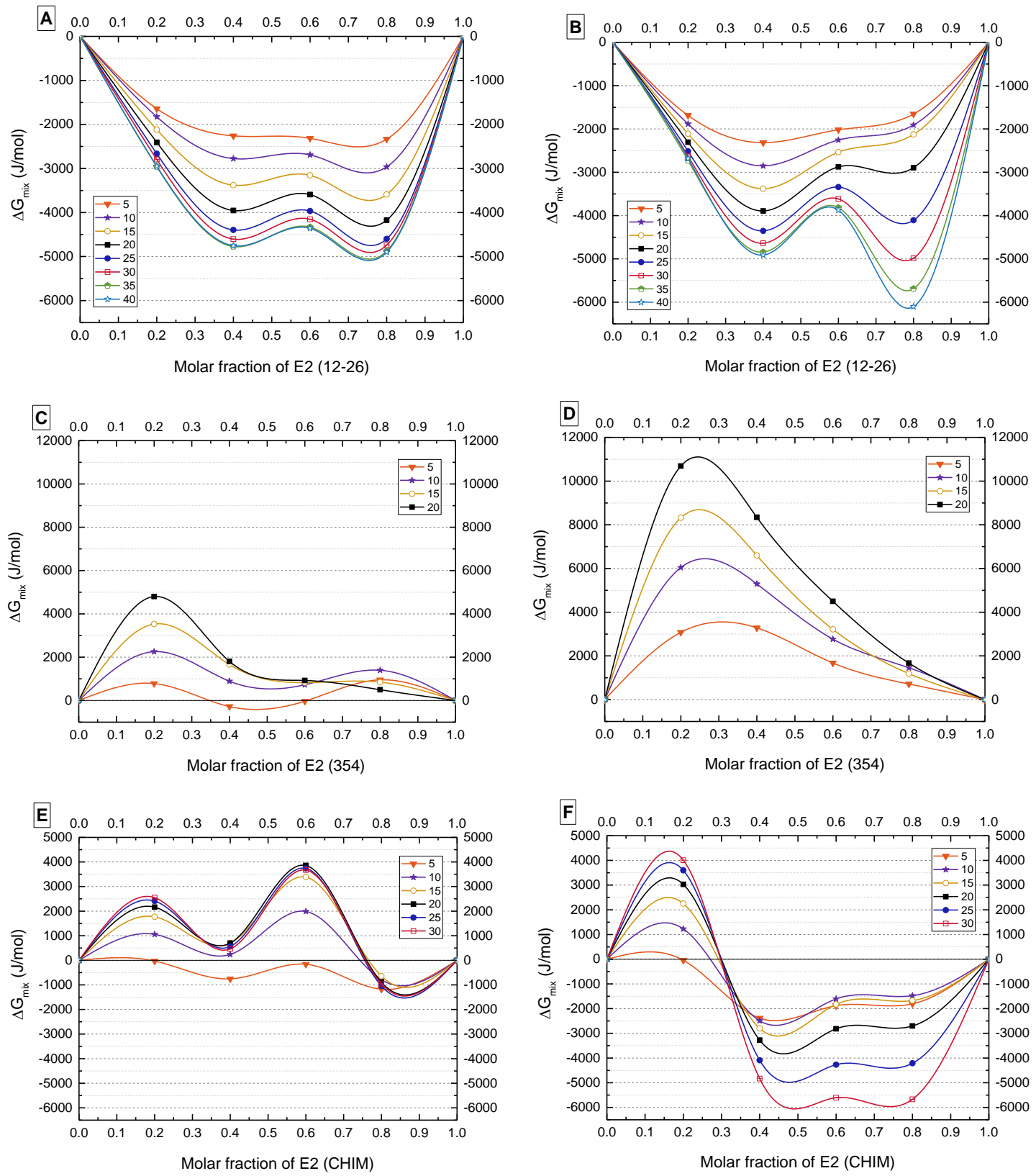
Graphical Abstract

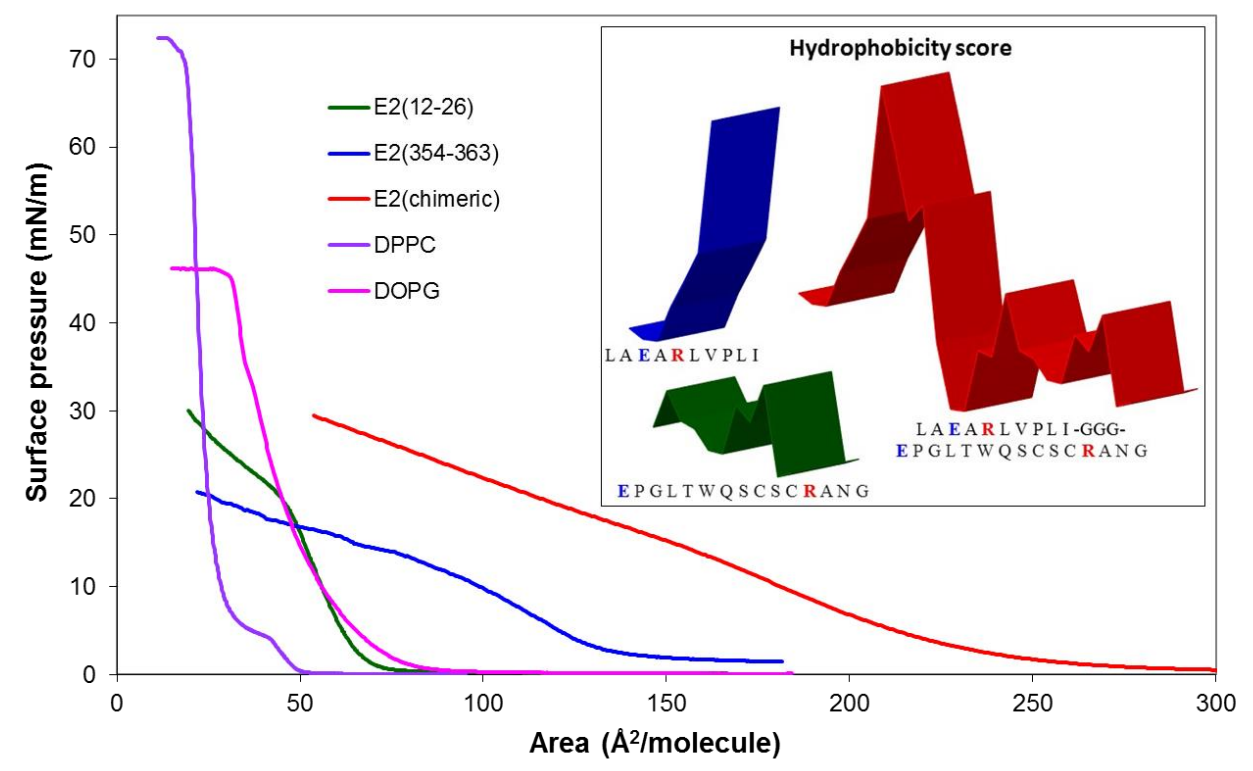

